\title{
Regulation of myogenic activation of p38 MAPK by TACE-mediated TNF $\alpha$ release
}

\section{Yi-Ping Li*, Airu Niu and Yefei Wen}

Department of Integrative Biology and Pharmacology, University of Texas Health Science Center, Houston, TX, USA

\author{
Edited by: \\ Ashok Kumar, University of \\ Louisville, USA \\ Reviewed by: \\ Ashok Kumar, University of \\ Louisville, USA \\ Yuji Ogura, St. Marianna University \\ School of Medicine, Japan \\ Zhenguo Wu, Hong Kong University \\ of Science \& Technology, China \\ ${ }^{*}$ Correspondence: \\ Yi-Ping Li, Department of Integrative \\ Biology and Pharmacology, \\ University of Texas Health Science \\ Center, 6431 Fannin Street, \\ Houston, TX 77030, USA \\ e-mail: yi-ping.li@uth.tmc.edu
}

The activation of p38 MAPK in myogenic precursor cells (MPCs) is a key signal for their exit of cell cycle and entry of the myogenic differentiation program. Therefore, identification of the signaling mechanism that activates p38 MAPK during this process is important for the understanding of the regulatory mechanism of muscle regeneration. This article reviews recent findings regarding the role of inflammatory cytokine tumor necrosis factor- $\alpha$ (TNF $\alpha$ ) as a key activator of p38 MAPK during myogenesis in an autocrine/paracrine fashion, and the signaling mechanisms that converge upon TNF $\alpha$ converting enzyme (TACE) to release TNF $\alpha$ from differentiating MPCs in response to diverse regenerative stimuli.

Keywords: muscle regeneration, satellite cells, differentiation, p38 MAPK, TNF $\alpha$, TACE
Skeletal muscle regeneration is vital for the maintenance of muscle homeostasis, the repair of injury and the adaptation to training. Skeletal muscle regeneration requires the re-initiation of the myogenic program that involves the sequential expression or repression of such transcription factors as Six1/4, Pax3/7, Myf5, MyoD, myogenin, and MRF4 to turn on muscle-specific gene expression in myogenic precursor cells (MPCs), known as satellite cells (Bentzinger et al., 2012). The execution of the myogenic program requires epigenetic regulations that control the activity of the aforementioned transcription factors precisely to establish and maintain the myogenic identity in quiescent MPCs and to enable the proper response to environmental cues in activated MPCs (Giordani and Puri, 2013).

A key player in epigenetic regulation of the myogenic program is p38 MAPK. Activation of p38 MAPK is essential for the initiation of myogenic differentiation in myoblasts and embryo (Cuenda and Cohen, 1999; Zetser et al., 1999; Puri et al., 2000; Wu et al., 2000; Cabane et al., 2003; Penn et al., 2004; de Angelis et al., 2005). Activated p38 MAPK mediates the transition of proliferating satellite cells into terminal differentiation and ensuing muscle-specific gene expression through multiple actions including the initiation of cell cycle exit by down-regulating Pax7, the activation of key myogenic transcription factors MyoD and MEF2, and the activation of chromatin remodeling to allow access of MyoD and MEF2 to the myogenic loci (Lluis et al., 2006; Giordani and Puri, 2013). In addition, the myogenesis-promoting role of p38 MAPK has been linked to its $\alpha$ subtype specifically (Cabane et al., 2003; Perdiguero et al., 2007; Palacios et al., 2010). Thus, p38 MAPK is considered a molecular switch for the activation of myogenic differentiation, and the signaling mechanism that mediates myogenic activation of $\mathrm{p} 38 \mathrm{MAPK}$ is of fundamental importance for myogenic gene expression. However, for a long period of time the signaling mechanism that mediates p38 MAPK activation in satellite cells during muscle regeneration was poorly understood. This review summarizes the recent literature that depicts a key role of TACE-mediated release of TNF $\alpha$ from MPCs in the activation of p38 MAPK during muscle regeneration.

\section{INFLAMMATION IS CRITICAL TO MUSCLE REGENERATION}

Myogenic activation of p38 MAPK is controlled either by the developmental program, as in embryonic myogenesis, or by environmental input, as in adult myogenesis associated with muscle regeneration. Muscle regeneration takes place in a highly inflammatory environment. Inflammation has been recognized as a key response to muscle injury required for muscle regeneration (Tidball, 1995, 2005). Infiltrated inflammatory cells, particularly macrophages, facilitate muscle regeneration via phagocytosis of cellular debris and release of soluble factors that promote satellite cell proliferation and differentiation (Cantini et al., 1994; Cantini and Carraro, 1995; Chazaud et al., 2003). Among those soluble factors, there are not only chemoattractants and growth factors that are traditionally recognized as factors promoting muscle regeneration but also cytokines that are known mainly as inflammatory mediators including TGF $\beta$, leukemia inhibitory factor (LIF) and IL-6 (Hawke and Garry, 2001; Charge and Rudnicki, 2004).

All the growth factors involved in muscle regeneration including fibroblast growth factor (FGF), insulin-like growth factor (IGF-I), hepatocyte growth factor (HGF), epidermal growth factor (EGF), and platelet-derived growth factor (PDGF) promote the proliferation of satellite cells. Most of them also inhibit the differentiation of satellite cells. Only IGF-I has been convincingly shown to promote both the proliferation and differentiation of satellite cells (Hawke and Garry, 2001; Charge and Rudnicki, 2004). However, IGF-I is not able to activate p38 MAPK or to induce myogenesis when p38 MAPK is inhibited (Wu et al., 2000). Some of the cytokines including TGF $\alpha$, LIF (Austin et al., 1992), and IL-6 (Cantini et al., 1995; Munoz-Canoves et al., 2013) also 
promote satellite cell proliferation. On the other hand, TGF $\beta$ inhibits differentiation (Massague et al., 1986; Olson et al., 1986). However, the inflammatory cytokine TNF $\alpha$ has emerged as a key mediator of myogenic differentiation due to its activation of p38 MAPK.

\section{TNF $\alpha$ RECEPTOR-MEDIATED SIGNALING IS REQUIRED FOR MYOGENESIS}

Several lines of evidence support a central role of TNF $\alpha$ in the activation of adult myogenesis. First, muscle regeneration takes place in an environment with elevated TNF $\alpha$ levels. Mammalian muscle constitutively synthesizes TNF $\alpha$ (Saghizadeh et al., 1996). Coinciding with the onset of muscle regeneration, TNF $\alpha$ level in injured muscle rises dramatically because of a strong increase in TNF $\alpha$ synthesis by injured myofibers as well as $\mathrm{TNF} \alpha$ release by infiltrating inflammatory cells (Tews and Goebel, 1996; De Bleecker et al., 1999; Zador et al., 2001; Warren et al., 2002). Importantly, myofiber synthesis of $\mathrm{TNF} \alpha$ is positively correlated to regenerating activity (Kuru et al., 2003). At the same time, there is an increase in $\mathrm{TNF} \alpha$ receptor expression in injured muscle fibers (De Bleecker et al., 1999; Zador et al., 2001), suggesting a physiological role for $\mathrm{TNF} \alpha$ receptor-mediated signaling in injured muscle. Further, $\mathrm{TNF} \alpha$ is constitutively expressed in $\mathrm{C} 2 \mathrm{C} 12$ myoblasts and a rapid increase of TNF $\alpha$ expression takes place during the early hours of differentiation, which is critical to muscle-specific gene expression, suggesting that $\mathrm{TNF} \alpha$ regulates myogenesis in an autocrine/paracrine fashion (Li and Schwartz, 2001). These data indicate an orchestrated effort by myocytes and inflammatory cells to increase $\mathrm{TNF} \alpha$ receptor-mediated signaling in MPCs during muscle regeneration.

Second, TNF $\alpha$ receptor-mediated signaling is critical to myogenesis in diverse muscle regeneration models. $\mathrm{TNF} \alpha$ receptor double-knockout ( $\mathrm{p} 55^{-} /^{-} \mathrm{p} 75^{-/-}$) impairs strength recovery of mouse muscle injured by freezing, which suggests the participation of TNF $\alpha$ in the regulation of muscle regeneration (Warren et al., 2002). In addition, it was observed in cardiotoxin-injured mouse muscle that TNF $\alpha$ receptor double-knockout increases the expression of Cyclin D1 and decreases the expression of p21 as well as the activation of $\mathrm{MEF} 2 \mathrm{C}$, resulting in a blockade of myogenin expression and impairment of muscle regeneration (Chen et al., 2005). These data suggest that TNF $\alpha$ receptor-mediated signaling is required for proliferating satellite cells to exit cell cycle and enter terminal differentiation. Subsequent in vitro studies confirmed this role of TNF $\alpha$. In cultured myoblasts with $\mathrm{TNF} \alpha$ receptor double-knockout the activation or expression of early myogenic markers MEF2C, p21 and myogenin are blocked, resulting in decreased expression of myosin heavy chain (MHC), when differentiation is induced by either serum withdraw (Chen et al., 2007) or mechanical stretch (Zhan et al., 2007). Further, addition of a TNF $\alpha$-neutralizing antibody to the culture medium of myoblasts recapitulates a critical role of myoblast-released autocrine $\mathrm{TNF} \alpha$ in the activation of myogenic differentiation. Conversely, addition of exogenous $\mathrm{TNF} \alpha$ to myoblast cultures, which mimics the elevated levels of $\mathrm{TNF} \alpha$ found in injured muscle, further increases myoblast differentiation (Chen et al., 2007). These observations support the concept that combined $\mathrm{TNF} \alpha$ release from myocytes and inflammatory cells in injured muscle promotes myogenesis. A more recent study by Palacios and colleagues further demonstrated that neutralizing TNF $\alpha$ in mdx mice blocks myogenesis by interfering with differentiationassociated repression of Pax7 levels which is essential for cell cycle exit and the progression of activated satellite cells in myogenic lineage (Palacios et al., 2010). Therefore, TNF $\alpha$ receptor-mediated signaling has a central role in the regulation of the exit of cell cycle and the initiation of myogenic differentiation in satellite cells.

Third, TNF $\alpha$ receptor-mediated signaling promotes myogenic differentiation through its activation of p38 MAPK. TNF $\alpha$ is one of the many activators of p38 MAPK (Zarubin and Han, 2005). In myocytes TNF $\alpha$ receptor-associated factor 6 (TRAF6) mediates p38 MAPK activation through Transforming growth factor $\beta$ activated kinase-1 (TAK1) (Xiao et al., 2012). However, whether $\mathrm{TNF} \alpha$ receptor-mediated signaling is critical to myogenic activation of p38 MAPK was unknown until such a role has been demonstrated in diverse models of muscle regeneration. In cardiotoxin-injured mouse muscle $\mathrm{TNF} \alpha$ receptor doubleknockout blocks the activation of p38 MAPK (Chen et al., 2005). Neutralizing TNF in mdx mice blocks p38 MAPK activation in regenerating mdx muscle (Palacios et al., 2010). Consistent to the in vivo findings, in cultured myoblasts $\mathrm{TNF} \alpha$ receptor doubleknockout or treatment with a TNF $\alpha$-neutralizing antibody blocks p38 MAPK activation, resulting in a blockade of myogenic differentiation similar to the effect of the pharmacological inhibitor of p38 MAPK, SB203580 (Chen et al., 2007; Zhan et al., 2007). Further, the activation of p38 MAPK has been shown to be essential to $\mathrm{TNF} \alpha$ receptor-mediated signaling to promote myogenic differentiation. Forced activation of p38 MAPK by the expression of a constitutively active MKK6 (MKK6bE) in the muscle of $\mathrm{TNF} \alpha$ receptor double-knockout mice rescues impaired myogenesis and muscle regeneration (Chen et al., 2007). These observations indicate that $\mathrm{TNF} \alpha$ receptor-mediated signaling promotes myogenesis through the activation of p38 MAPK.

\section{TACE-MEDIATED AUTOCRINE TNF $\alpha$ RELEASE FROM MYOBLASTS ACTIVATES p38 MAPK AND MYOGENESIS}

$\mathrm{TNF} \alpha$ is synthesized as a $26 \mathrm{kDa}$ transmembrane pro-protein and released as a $17 \mathrm{kDa}$ free peptide into extracellular space upon cleavage primarily by TNF $\alpha$ converting enzyme (TACE). TACE, also known as A disintegrin and metalloprotease (ADAM) 17 , is a ubiquitous transmembrane protein that belongs to the ADAM family of disintegrin metalloproteinases (Blobel, 1997; Black, 2002). The cleavage of TNF $\alpha$ from the plasma membrane by TACE allows the release of free $\mathrm{TNF} \alpha$ in muscle from infiltrating inflammatory cells, primarily macrophages, as well as myocytes as a paracrine or autocrine regulator. TACE activity is regulated posttranscriptionally by cellular signaling events (Zhang et al., 2000, 2001; Fan et al., 2003), hence, TACE could be a rate-limiting regulator of $\mathrm{TNF} \alpha$-mediate signaling in myogenesis. Importantly, in cardiotoxin-injured muscle, there is not only an increase in TNF $\alpha$ synthesis but also an increase in TNF $\alpha$ cleavage, which starts within 1 day and reaches the peak level around day 3 of injury, coinciding with the activation of satellite cells and the initiation of myogenic differentiation (Chen et al., 2007). TNF $\alpha$ was also shown released by cultured proliferating myoblasts at a low level, which is significantly increased upon 
differentiation and lasts for at least 2 days, when myogenic gene expression is being initiated (Chen et al., 2007). Neutralizing the $\mathrm{TNF} \alpha$ released into the culture medium blocks p38 MAPK activation during myoblast differentiation induced by either serumwithdraw (Chen et al., 2007) or mechanical stretch (Zhan et al., 2007). Further, a dramatic increase in TACE activity is observed in differentiating myoblasts, which is rate limiting for the activation of p38 MAPK and subsequent myogenic differentiation (Zhan et al., 2007). Therefore, TACE-mediated autocrine TNF $\alpha$ release from myoblasts activates p38 MAPK and myogenesis.

\section{TACE ACTIVITY IN MYOBLASTS IS REGULATED BY DISTINCT SIGNALING MECHANISMS SPECIFIC TO THE NATURE OF MYOGENIC STIMULUS}

Given that TACE-mediated autocrine TNF $\alpha$ release is a key step for the activation of p38 MAPK in differentiating myoblasts, there must be intrinsic mechanisms that control the release of TNF $\alpha$ through regulating TACE activity in response to myogenic stimuli. TACE activity is normally repressed by its physiological inhibitor, tissue inhibitor of metalloproteinase 3 (TIMP3), a member of the tissue inhibitor of metalloproteinase family that plays an important role in the regulation of inflammation (Black, 2004). TIMP3 is the only one of four TIMPs that binds to the extracellular matrix (Mohammed et al., 2003) and inhibits TACE activity through chelating the extracellular active-site zinc with its N-terminus (Gomis-Rüth et al., 1997; Amour et al., 1998; Lee et al., 2005). Notably, TIMP3 is constitutively expressed in muscle cells (Leco et al., 1994), which suggests a physiological role for TIMP3 in muscle cells. In searching for the mechanisms that regulate TACE activity during myogenesis, Liu et al. (2010) recently discovered that in mouse muscle undergoing regeneration induced by cardiotoxin injury or functional overloading, TIMP3 expression at mRNA and protein levels is dramatically down-regulated within 1 day, and then recovered to normal level when regeneration is complete. The down-regulation of TIMP3 takes place in activated satellite cells. Similar down-regulation of TIMP3 is observed in cultured myoblasts that are differentiating in low-serum medium. Ectopic expression of TIMP3 in myoblasts or muscle that counters TIMP3 down-regulation blocks p38 MAPK activation and myogenic differentiation. Further, TIMP3 down-regulation in differentiating myoblasts is mediated by microRNA-206, a myogenesis-promoting microRNA that is induced during myoblast differentiation (Kim et al., 2006; Rao et al., 2006). Thus, constitutively expressed TIMP3 acts as a gatekeeper of myogenic differentiation that helps to prevent premature differentiation and maintain the satellite cell pool. The down-regulation of TIMP3 opens the gate of differentiation by allowing TACE to release TNF $\alpha$ that activates p38 MAPK.

However, the down-regulation of TIMP3, which requires many hours to take place, does not explain the rapid activation of p38 MAPK by TNF $\alpha$ observed in mechanically stretched myoblasts (Zhan et al., 2007). More recently, Niu and colleagues described a signaling mechanism of rapid activation of TACE in muscle in response to mechanical loading involving the nonreceptor tyrosine kinase Src. Src plays an important role in the transduction of mechanical stimulation into biochemical signaling in a variety of load-sensitive cells (Han et al., 2004; Wang et al., 2005). In cells that are mechanically stimulated, Src undergoes phosphorylation and dephosphorylation rapidly, which activates Src. Activated Src in turn activates its downstream effectors through tyrosine phosphorylation (Sai et al., 1999). Niu et al. (2013) discovered that Src is rapidly activated in mechanically stretched myoblasts. Src then quickly phosphorylates TACE that possesses the structural features of Src substrates in its intracellular tail including a potential SH3-binding motif $\left(\mathrm{P}^{731} \mathrm{APQTPGR}{ }^{738}\right)$ adjacent to a putative tyrosine phosphorylation motif $\left(\mathrm{K}^{696} \mathrm{KLDKQYESL}^{705}\right)$. Utilizing an antibody raised against this motif with phosphorylated Tyr-702 residue, these authors demonstrated that Src phosphorylates Tyr-702 upon mechanical stimulation, which activates TACE. Expression of a TACE mutant in which the Tyr-702 residue is replaced by alanine blocks TACE-activated TNF $\alpha$ release, p38 MAPK activation and differentiation in mechanically stretched myoblasts. Further, Src deficiency suppressed activation of p38 MAPK and myogenesis in mechanically stretched myoblasts as well as in satellite cells of overloaded soleus in mice. Consequently, overloadinginduced muscle regeneration is impaired in Src-deficient mice. The presence of such stimulus-specific signaling mechanisms that regulate TACE release of autocrine TNF $\alpha$ from MPCs provides further support for TNF $\alpha$ as a key regulator of the myogenic program responsible for the activation of $\mathrm{p} 38$ MAPK during myogenesis.

\section{OTHER CONSIDERATIONS}

It is noteworthy that the effect of TNF $\alpha$ on myogenic differentiation is highly complex. The effect of TNFa on myoblast differentiation is bimodal. At physiological concentrations found in injured muscle (up to $0.05 \mathrm{ng} / \mathrm{ml}$ ), exogenously added TNF $\alpha$ promotes myoblast differentiation. However, at higher concentrations that are seen in inflammatory diseases exogenously added TNF $\alpha$ inhibits myoblast differentiation, despite that its activation of p38 MAPK is intact (Chen et al., 2007). Indeed, a number a studies that employed high concentrations of TNF $\alpha$ reported similar inhibitory effect of TNF $\alpha$ on myoblast differentiation (Guttridge et al., 2000; Langen et al., 2001; Trendelenburg et al., 2012) or muscle regeneration (Moresi et al., 2008). The paradoxical effects of $\mathrm{TNF} \alpha$ on myogenesis illustrate the importance of distinguishing its physiological role from its pathological roles.

Another issue of significance is that TNF $\alpha$ receptor-mediated signaling is not required for embryonic myogenesis. Mice with $\mathrm{TNF} \alpha$ receptor double-knockout develop seemly normal muscle. Myogenic activation of p38 MAPK during development is likely mediated by the cell surface receptor Cdo (Kang et al., 2008) or by amphoterin (HMGB1) through engaging the receptor for advanced glycation end products (RAGE), whose expression is developmentally regulated (Sorci et al., 2004).

Further, p38 MAPK has been shown to promote satellite cell activation and proliferation (Jones et al., 2005) through an asymmetric activation pattern (Troy et al., 2012). However, whether $\mathrm{TNF} \alpha$ is responsible for $\mathrm{p} 38 \mathrm{MAPK}$ activation during these events is unknown. 


\section{CONCLUSIONS}

Recent progress indicates that TACE-released autocrine TNF $\alpha$ from MPCs is a key mediator of p38 MAPK activation that initiates myogenic differentiation through epigenetic regulations. Emerging evidence also revealed that MPCs respond to diverse environmental cues of muscle regeneration by activating p38 MAPK through the activation of TACE release of autocrine $\mathrm{TNF} \alpha$ through at least two distinct signaling pathways, namely, the down-regulation of TIMP3 by miR-206 or the activation of TACE by Src in a stimulus-dependent manner. Therefore, TACEmediated $\mathrm{TNF} \alpha$ release from MPCs plays a key role in the reinitiation of the myogenic program during muscle regeneration.

\section{ACKNOWLEDGMENT}

This work is supported by Grant R01 AR049022 from National Institute of Arthritis, Musculoskeletal and skin Diseases to YiPing Li.

\section{REFERENCES}

Amour, A., Slocombe, P. M., Webster, A., Butler, M., Knight, C. G., Smith, B. J., et al. (1998). TNF-alpha converting enzyme (TACE) is inhibited by TIMP-3. FEBS Lett. 435, 39-44. doi: 10.1016/S0014-5793(98)01031-X

Austin, L., Bower, J., Kurek, J., and Vakakis, N. (1992). Effects of leukaemia inhibitory factor and other cytokines on murine and human myoblast proliferation. J. Neurol. Sci. 112, 185-191. doi: 10.1016/0022-510X(92)90149-F

Bentzinger, C. F., Wang, Y. X., and Rudnicki, M. A. (2012). Building muscle: molecular regulation of myogenesis. Cold Spring Harb. Perspect. Biol. 4, 1-16. doi: 10.1101/cshperspect.a008342

Black, R. A. (2002). Tumor necrosis factor-alpha converting enzyme. Int. J. Biochem. Cell Biol. 34, 1-5. doi: 10.1016/S1357-2725(01)00097-8

Black, R. A. (2004). TIMP3 checks inflammation. Nat. Genet. 36, 934-935. doi: 10.1038/ng0904-934

Blobel, C. P. (1997). Metalloprotease-disintegrins: links to cell adhesion and cleavage of TNF alpha and Notch. Cell 90, 589-592. doi: 10.1016/S00928674(00)80519-X

Cabane, C., Englaro, W., Yeow, K., Ragno, M., and Derijard, B. (2003). Regulation of $\mathrm{C} 2 \mathrm{C} 12$ myogenic terminal differentiation by MKK3/p38alpha pathway. Am. J. Physiol. Cell Physiol. 284, C658-C666. doi: 10.1152/ajpcell.00078.2002

Cantini, M., and Carraro, U. (1995). Macrophage-released factor stimulates selectively myogenic cells in primary muscle culture. J. Neuropathol. Exp. Neurol. 54, 121-128. doi: 10.1097/00005072-199501000-00014

Cantini, M., Massimino, M. L., Bruson, A., Catani, C., Dalla Libera, L., and Carraro, U. (1994). Macrophages regulate proliferation and differentiation of satellite cells. Biochem. Biophys. Res. Commun. 202, 1688-1696. doi: 10.1006/bbrc. 1994.2129

Cantini, M., Massimino, M. L., Rapizzi, E., Rossini, K., Catani, C., Dalla Libera, L., et al. (1995). Human satellite cell proliferation in vitro is regulated by autocrine secretion of IL-6 stimulated by a soluble factor(s) released by activated monocytes. Biochem. Biophys. Res. Commun. 216, 49-53. doi: 10.1006/bbrc.1995.2590

Charge, S. B., and Rudnicki, M. A. (2004). Cellular and molecular regulation of muscle regeneration. Physiol. Rev. 84, 209-238. doi: 10.1152/physrev.00019.2003

Chazaud, B., Sonnet, C., Lafuste, P., Bassez, G., Rimaniol, A. C., Poron, F., et al. (2003). Satellite cells attract monocytes and use macrophages as a support to escape apoptosis and enhance muscle growth. J. Cell Biol. 163, 1133-1143. doi: $10.1083 /$ jcb.200212046

Chen, S. E., Gerken, E., Zhang, Y., Zhan, M., Mohan, R. K., Li, A. S., et al. (2005). Role of TNF-\{alpha\} signaling in regeneration of cardiotoxin-injured muscle. Am. J. Physiol. Cell Physiol. 289, C1179-C1187. doi: 10.1152/ajpcell.00062.2005

Chen, S. E., Jin, B., and Li, Y. P. (2007). TNF-alpha regulates myogenesis and muscle regeneration by activating p38 MAPK. Am. J. Physiol. Cell Physiol. 292, C1660-C1671. doi: 10.1152/ajpcell.00486.2006

Cuenda, A., and Cohen, P. (1999). Stress-activated protein kinase-2/p38 and a rapamycin-sensitive pathway are required for $\mathrm{C} 2 \mathrm{C} 12$ myogenesis. J. Biol. Chem. 274, 4341-4346. doi: 10.1074/jbc.274.7.4341 de Angelis, L., Zhao, J., Andreucci, J. J., Olson, E. N., Cossu, G., and McDermott, J. C. (2005). Regulation of vertebrate myotome development by the p38 MAP kinase-MEF2 signaling pathway. Dev. Biol. 283, 171-179. doi: 10.1016/j.ydbio.2005.04.009

De Bleecker, J. L., Meire, V. I., Declercq, W., and Van Aken, E. H. (1999). Immunolocalization of tumor necrosis factor-alpha and its receptors in inflammatory myopathies. Neuromuscul. Disord. 9, 239-246. doi: 10.1016/S09608966(98)00126-6

Fan, H., Turck, C. W., and Derynck, R. (2003). Characterization of growth factorinduced serine phosphorylation of tumor necrosis factor-alpha converting enzyme and of an alternatively translated polypeptide. J. Biol. Chem. 278, 18617-18627. doi: 10.1074/jbc.M300331200

Giordani, L., and Puri, P. L. (2013). Epigenetic control of skeletal muscle regeneration: integrating genetic determinants and environmental changes. FEBS J. 280, 4014-4025. doi: 10.1111/febs.12383

Gomis-Rüth, F. X., Maskos, K., Betz, M., Bergner, A., Huber, R., Suzuki, K., et al. (1997). Mechanism of inhibition of the human matrix metalloproteinase stromelysin-1 by TIMP-1. Nature 389, 77-81. doi: 10.1038/37995

Guttridge, D. C., Mayo, M. W., Madrid, L. V., Wang, C. Y., and Baldwin, A. S. Jr. (2000). NF-kappaB-induced loss of MyoD messenger RNA: possible role in muscle decay and cachexia. Science 289, 2363-2366. doi: 10.1126/science.289.5488.2363

Han, B., Bai, X. H., Lodyga, M., Xu, J., Yang, B. B., Keshavjee, S., et al. (2004). Conversion of mechanical force into biochemical signaling. J. Biol. Chem. 279, 54793-54801. doi: 10.1074/jbc.M406880200

Hawke, T. J., and Garry, D. J. (2001). Myogenic satellite cells: physiology to molecular biology. J. Appl. Physiol. 91, 534-551.

Jones, N. C., Tyner, K. J., Nibarger, L., Stanley, H. M., Cornelison, D. D., Fedorov, Y. V., et al. (2005). The p38alpha/beta MAPK functions as a molecular switch to activate the quiescent satellite cell. J. Cell Biol. 169, 105-116. doi: 10.1083/jcb.200408066

Kang, J. S., Bae, G. U., Yi, M. J., Yang, Y. J., Oh, J. E., Takaesu, G., et al. (2008). A Cdo-Bnip-2-Cdc42 signaling pathway regulates p38alpha/beta MAPK activity and myogenic differentiation. J. Cell Biol. 182, 497-507. doi: $10.1083 /$ jcb.200801119

Kim, H. K., Lee, Y. S., Sivaprasad, U., Malhotra, A., and Dutta, A. (2006). Musclespecific microRNA miR-206 promotes muscle differentiation. J. Cell Biol. 174, 677-687. doi: $10.1083 /$ jcb. 200603008

Kuru, S., Inukai, A., Kato, T., Liang, Y., Kimura, S., and Sobue, G. (2003). Expression of tumor necrosis factor-alpha in regenerating muscle fibers in inflammatory and non-inflammatory myopathies. Acta Neuropathol. 105, 217-224. doi: 10.1007/s00401-002-0635-4

Langen, R. C., Schols, A. M., Kelders, M. C., Wouters, E. F., and Janssen-Heininger, Y. M. (2001). Inflammatory cytokines inhibit myogenic differentiation through activation of nuclear factor-kappaB. FASEB J. 15, 1169-1180. doi: 10.1096/fj.000463

Leco, K. J., Khokha, R., Pavloff, N., Hawkes, S. P., and Edwards, D. R. (1994). Tissue inhibitor of metalloproteinases-3 (TIMP-3) is an extracellular matrix-associated protein with a distinctive pattern of expression in mouse cells and tissues. J. Biol. Chem. 269, 9352-9360.

Lee, M. H., Rapti, M., and Murphy, G. (2005). Total conversion of tissue inhibitor of metalloproteinase (TIMP) for specific metalloproteinase targeting: fine-tuning TIMP-4 for optimal inhibition of tumor necrosis factor- $\alpha$-converting enzyme. J. Biol. Chem. 280, 15967-15975. doi: 10.1074/jbc.M500897200

Li, Y. P., and Schwartz, R. J. (2001). TNF-alpha regulates early differentiation of $\mathrm{C} 2 \mathrm{C} 12$ myoblasts in an autocrine fashion. FASEB J. 15, 1413-1415. doi: 10.1096/fj.00-0632fje

Liu, H., Chen, S. E., Jin, B., Carson, J. A., Niu, A., Durham, W., et al. (2010). TIMP3: a physiological regulator of adult myogenesis. J. Cell Sci. 123, 2914-2921. doi: $10.1242 /$ jcs. 057620

Lluis, F., Perdiguero, E., Nebreda, A. R., and Munoz-Canoves, P. (2006). Regulation of skeletal muscle gene expression by p38 MAP kinases. Trends Cell Biol. 16, 36-44. doi: 10.1016/j.tcb.2005.11.002

Massague, J., Cheifetz, S., Endo, T., and Nadal-Ginard, B. (1986). Type beta transforming growth factor is an inhibitor of myogenic differentiation. Proc. Natl. Acad. Sci. U.S.A. 83, 8206-8210. doi: 10.1073/pnas.83.21.8206

Mohammed, F. F., Smookler, D. S., and Khokha, R. (2003). Metalloproteinases, inflammation, and rheumatoid arthritis. Ann. Rheum. Dis. 62(Suppl 2), ii43-ii47. doi: 10.1136/ard.62.suppl_2.ii43 
Moresi, V., Pristera, A., Scicchitano, B. M., Molinaro, M., Teodori, L., Sassoon, D., et al. (2008). Tumor necrosis factor-alpha inhibition of skeletal muscle regeneration is mediated by a caspase-dependent stem cell response. Stem Cells 26, 997-1008. doi: 10.1634/stemcells.2007-0493

Munoz-Canoves, P., Scheele, C., Pedersen, B. K., and Serrano, A. L. (2013). Interleukin-6 myokine signaling in skeletal muscle: a double-edged sword? FEBS J. 280, 4131-4148. doi: 10.1111/febs. 12338

Niu, A., Wen, Y., Liu, H., Zhan, M., Jin, B., and Li, Y. P. (2013). Src mediates the mechanical activation of myogenesis by activating TNFalpha-converting enzyme. J. Cell Sci. 126, 4349-4357. doi: 10.1242/jcs.125328

Olson, E. N., Sternberg, E., Hu, J. S., Spizz, G., and Wilcox, C. (1986). Regulation of myogenic differentiation by type beta transforming growth factor. J. Cell Biol. 103, 1799-1805. doi: 10.1083/jcb.103.5.1799

Palacios, D., Mozzetta, C., Consalvi, S., Caretti, G., Saccone, V., Proserpio, V., et al. (2010). TNF/p38alpha/polycomb signaling to Pax7 locus in satellite cells links inflammation to the epigenetic control of muscle regeneration. Cell Stem Cell 7 , 455-469. doi: 10.1016/j.stem.2010.08.013

Penn, B. H., Bergstrom, D. A., Dilworth, F. J., Bengal, E., and Tapscott, S. J. (2004). A MyoD-generated feed-forward circuit temporally patterns gene expression during skeletal muscle differentiation. Genes Dev. 18, 2348-2353. doi: 10.1101/gad.1234304

Perdiguero, E., Ruiz-Bonilla, V., Gresh, L., Hui, L., Ballestar, E., Sousa-Victor, P., et al. (2007). Genetic analysis of p38 MAP kinases in myogenesis: fundamental role of p38alpha in abrogating myoblast proliferation. EMBO J. 26, 1245-1256. doi: $10.1038 /$ sj.emboj.7601587

Puri, P. L., Wu, Z., Zhang, P., Wood, L. D., Bhakta, K. S., Han, J., et al. (2000) Induction of terminal differentiation by constitutive activation of p38 MAP kinase in human rhabdomyosarcoma cells. Genes Dev. 14, 574-584. doi: 10.1101/gad.14.5.574

Rao, P. K., Kumar, R. M., Farkhondeh, M., Baskerville, S., and Lodish, H. F. (2006). Myogenic factors that regulate expression of muscle-specific microRNAs. Proc. Natl. Acad. Sci. U.S.A. 103, 8721-8726. doi: 10.1073/pnas.0602831103

Saghizadeh, M., Ong, J. M., Garvey, W. T., Henry, R. R., and Kern, P. A. (1996). The expression of TNF alpha by human muscle. Relationship to insulin resistance. $J$. Clin. Invest. 97, 1111-1116. doi: 10.1172/JCI118504

Sai, X., Naruse, K., and Sokabe, M. (1999). Activation of pp60(src) is critical for stretch-induced orienting response in fibroblasts. J. Cell Sci. 112(Pt 9), 1365-1373.

Sorci, G., Riuzzi, F., Arcuri, C., Giambanco, I., and Donato, R. (2004). Amphoterin stimulates myogenesis and counteracts the antimyogenic factors basic fibroblast growth factor and S100B via RAGE binding. Mol. Cell. Biol. 24, 4880-4894. doi: 10.1128/MCB.24.11.4880-4894.2004

Tews, D. S., and Goebel, H. H. (1996). Cytokine expression profile in idiopathic inflammatory myopathies. J. Neuropathol. Exp. Neurol. 55, 342-347. doi: 10.1097/00005072-199603000-00009

Tidball, J. G. (1995). Inflammatory cell response to acute muscle injury. Med. Sci. Sports Exerc. 27, 1022-1032. doi: 10.1249/00005768-199507000-00011

Tidball, J. G. (2005). Inflammatory processes in muscle injury and repair. Am. J. Physiol. Regul. Integr. Comp. Physiol. 288, R345-R353. doi: 10.1152/ajpregu.00454.2004

Trendelenburg, A. U., Meyer, A., Jacobi, C., Feige, J. N., and Glass, D. J. (2012). TAK-1/p38/nNFkappaB signaling inhibits myoblast differentiation by increasing levels of Activin A. Skelet. Muscle 2, 3. doi: 10.1186/2044-5040-2-3

Troy, A., Cadwallader, A. B., Fedorov, Y., Tyner, K., Tanaka, K. K., and Olwin, B. B. (2012). Coordination of satellite cell activation and self-renewal by
Par-complex-dependent asymmetric activation of p38alpha/beta MAPK. Cell Stem Cell 11, 541-553. doi: 10.1016/j.stem.2012.05.025

Wang, Y., Botvinick, E. L., Zhao, Y., Berns, M. W., Usami, S., Tsien, R. Y., et al. (2005). Visualizing the mechanical activation of Src. Nature 434, 1040-1045. doi: $10.1038 /$ nature 03469

Warren, G. L., Hulderman, T., Jensen, N., McKinstry, M., Mishra, M., Luster, M. I., et al. (2002). Physiological role of tumor necrosis factor alpha in traumatic muscle injury. FASEB J. 16, 1630-1632. doi: 10.1096/fj.020187fje

Wu, Z., Woodring, P. J., Bhakta, K. S., Tamura, K., Wen, F., Feramisco, J. R., et al. (2000). p38 and extracellular signal-regulated kinases regulate the myogenic program at multiple steps. Mol. Cell. Biol. 20, 3951-3964. doi: 10.1128/MCB.20.11.3951-3964.2000

Xiao, F., Wang, H., Fu, X., Li, Y., and Wu, Z. (2012). TRAF6 promotes myogenic differentiation via the TAK1/p38 mitogen-activated protein kinase and Akt pathways. PLoS ONE 7:e34081. doi: 10.1371/journal.pone.0034081

Zador, E., Mendler, L., Takacs, V., de Bleecker, J., and Wuytack, F. (2001). Regenerating soleus and extensor digitorum longus muscles of the rat show elevated levels of TNF-alpha and its receptors, TNFR-60 and TNFR-80. Muscle Nerve 24, 1058-1067. doi: 10.1002/mus.1110

Zarubin, T., and Han, J. (2005). Activation and signaling of the p38 MAP kinase pathway. Cell Res. 15, 11-18. doi: 10.1038/sj.cr.7290257

Zetser, A., Gredinger, E., and Bengal, E. (1999). p38 mitogen-activated protein kinase pathway promotes skeletal muscle differentiation. Participation of the Mef2c transcription factor. J. Biol. Chem. 274, 5193-5200. doi: 10.1074/jbc.274.8.5193

Zhan, M., Jin, B., Chen, S. E., Reecy, J. M., and Li, Y. P. (2007). TACE release of TNF-alpha mediates mechanotransduction-induced activation of p38 MAPK and myogenesis. J. Cell Sci. 120, 692-701. doi: 10.1242/jcs.03372

Zhang, Z., Kolls, J. K., Oliver, P., Good, D., Schwarzenberger, P. O., Joshi, M. S., et al. (2000). Activation of tumor necrosis factor-alpha-converting enzyme-mediated ectodomain shedding by nitric oxide. J. Biol. Chem. 275, 15839-15844. doi: 10.1074/jbc.M000604200

Zhang, Z., Oliver, P., Lancaster, J. R. Jr., Schwarzenberger, P. O., Joshi, M. S., Cork, J., et al. (2001). Reactive oxygen species mediate tumor necrosis factor alphaconverting, enzyme-dependent ectodomain shedding induced by phorbol myristate acetate. FASEB J. 15, 303-305. doi: 10.1096/fj.00-0371fje

Conflict of Interest Statement: The authors declare that the research was conducted in the absence of any commercial or financial relationships that could be construed as a potential conflict of interest.

Received: 11 April 2014; paper pending published: 05 May 2014; accepted: 07 May 2014; published online: 23 May 2014.

Citation: Li Y-P, Niu A and Wen Y (2014) Regulation of myogenic activation of $p 38$ MAPK by TACE-mediated TNF $\alpha$ release. Front. Cell Dev. Biol. 2:21. doi: 10.3389/ fcell.2014.00021

This article was submitted to Molecular Medicine, a section of the journal Frontiers in Cell and Developmental Biology.

Copyright (C) $2014 \mathrm{Li}$, Niu and Wen. This is an open-access article distributed under the terms of the Creative Commons Attribution License (CC BY). The use, distribution or reproduction in other forums is permitted, provided the original author(s) or licensor are credited and that the original publication in this journal is cited, in accordance with accepted academic practice. No use, distribution or reproduction is permitted which does not comply with these terms. 